\title{
SLEEP QUALITY AND COGNITIVE DISORDER AMONG ACUTE STROKE PATIENTS FROM COASTAL AREAS IN NORTH SULAWESI
}

\author{
Sekplin A. S. Sekeon ${ }^{1)}$, Finny Warouw'1), Eva Mantjoro'), \\ Junita M. P. Sampoerno²) \\ 1)Faculty of Public Health, Universitas Sam Ratulangi \\ 2)Division of Neuro-behavior, Department of Neurology, \\ Faculty of Medicine, Universitas Sam Ratulangi
}

\begin{abstract}
Background: Sleep quality is considered as one of the non-conventional risk factors for stroke. Cognitive disorder is prevalent among stroke survivors. There is limited data on the association between sleep quality and cognitive disorder among stroke patients from coastal eastern part of Indonesia. The objective of the study was to analyze the association between sleep quality and cognitive disorder among acute stroke patients from coastal areas in North Sulawesi.

Subjects and Method: This was a hospital-based cross-sectional study carried out at Prof. dr. R. D. Kandou General Hospital of Manado, from May to June 2018. A sample of 39 acute stroke patients were selected for this study with some eligibility criteria. The dependent variable was cognitive disorder measured by Mini Mental Status Examination (MMSE). The independent variable was sleep quality measured by the Pittsburg Sleep Quality Index (PSQI). Stroke was diagnosed from history taking, physical examination, and neuroimaging study. The data were analyzed by chi square test and Odd Ratio as the measure of association.

Results: Sample characteristics were as follows: Age (Mean= 59.10; SD=10.43), male (51.3\%), high school (48.7\%), homemaker/housewife (25.6\%), residence in Manado (61.5\%), poor sleep quality a month prior to stroke (79.5\%), cognitive disorder after stroke (53.8\%). Stroke patients with poor sleep quality were 2.3 times more likely to experience cognitive disorder than counterparts with good quality of sleep $(\mathrm{OR}=2.30 ; 95 \% \mathrm{CI}=0.46$ to $11.42 ; \mathrm{p}=0.290)$.

Conclusion: Majority of acute stroke patients from coastal areas in North Sulawesi experience poor sleep quality. There is an association between sleep quality and cognitive disorder among acute stroke patients, but it is not statistically significant.
\end{abstract}

Keywords: sleep quality, cognitive disorder, acute stroke.

\section{Correspondence:}

Sekplin A. S. Sekeon. Faculty of Public Health, Universitas Sam Ratulangi, Manado, North Sumatera. Email: sekplin@yahoo.com.

Mobile: 081244058656

The 4th International Conference on Public Health Best Western Premier Hotel, Solo, Indonesia, August 29-30, 2018 | 297 https://doi.org/10.26911/theicph.2018.05.11 